\title{
Mitos, crenças e rodoviarismo na Amazônia brasileira
}

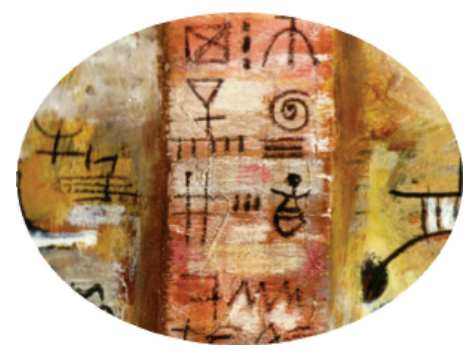

Marcelo da Silveira Rodrigues

\section{Resumo}

As mitologias têm uma função na formação do ethos social, tais elementos servem de instrumentos para moldar o pensamento comum. $\mathrm{Na}$ sociedade moderna o mundo mágico perde espaço e permite com que a racionalidade assuma este instrumento na construção do todo social. No caso, a desconstrução da mitologia tradicional amazônica e sua substituição pelo mito rodoviarista do desenvolvimento.

Palavras-chave: Amazônia; rodoviarismo; imaginário; mito.

\begin{abstract}
The mythologies have a role in shaping the social ethos, these elements serve as instruments for shaping the common thought. In modern society the magical world loses ground and lets the rationality assume that instrument in the construction of the social whole. In this case, the deconstruction of the traditional Amazonian mythology and its replacement by road-transport development.
\end{abstract}

Keywords: Amazonian; road-transport; imaginary; myth. 


\section{Introdução}

Em toda e qualquer sociedade seja antiga ou moderna, ocidental ou não ocidental, letrada ou não letrada etc., os mitos fazem parte de suas constituições básicas, se dando de formas diversas, de acordo com a especificidade geográfica, social e histórica de cada uma. Assim, inúmeras mitologias são conhecidas, umas mais outras menos, no mundo globalizado da atualidade, lendas gregas, nórdicas e romanas talvez sejam as mais difundidas pelo apelo cinematográfico e literário que têm ${ }^{1}$, até mesmo por serem três culturas, de alguma forma, fundamentais na fundação da sociedade ocidental moderna. Outras mitologias, menos populares globalmente, como as ameríndias ou africanas também coexistem ou coexistiram com essas contrapartes mais famosas e exerceram a mesma função fundadora que aquelas em suas respectivas sociedades. Assim, Zeus, Júpter, Odin, Exu e a Cobra Grande ${ }^{2}$ são todos entes mitológicos de suas sociedades e cada um deles, respeitando suas peculiaridades, toma para si a função de produção de um conhecimento socialmente relevante, ou melhor, de valores socialmente aceitos.

Mitologias religiosas também foram e são de fundamental importância na formação dos preceitos sociais vigentes em cada comunidade, assim, a coerção divina advinda das grandes religiões monoteístas que se tronaram hegemônicas no mundo, como o cristianismo, por exemplo, se faz presente nas sociedades que sofrem influência dessas religiões. A Bíblia sagrada, nas comunidades cristãs, com suas diversas histórias mitológicas, prega a aceitação dos "dez mandamentos" como forma de salvação do crente, tendo assim uma função coercitiva em relação aos valores socialmente aceitos e válidos. "Não matarás" ou "Não cobiçarás a mulher do próximo" nada mais são do que regras de boa covivência segundo os preceitos cristãos aceitos, no primeiro caso no sentido de pacificação social, enquanto que no segundo se dá a pregação da monogamia como melhor meio de relação entre homens e mulheres $^{3}$. Estes preceitos surgiram primeiro no contexto mitológico da Bíblia, ou seja, se baseando na crença e posteriormente se tornando leis de regulamentação social.

196 Somanlu, ano 11, n. 1, jan./jun. 2011 
O que se pretende, portanto aqui, é demonstrar como mitos e crenças são cunhados no contexto social, assim eles têm funções sociais, e dessa maneira foram e são de suma importância para toda e qualquer sociedade e em qualquer tempo. Através dos preceitos sociológicos de Émile Durkheim (1999) é possível argumentar que essas construções mágico-religiosas têm como função a criação ou formação do ente socializado que segue os preceitos morais de sua sociedade a partir do processo coercitivo da educação. São assim fundamentais na comunhão de cada sociedade.

\section{Mito e Coerção Social}

A utilização da mitologia é, como visto, algo usual como meio coercitivo no contexto social. De acordo com o antropólogo francês Claude LéviStrauss em seu texto "A ciência do concreto" presente no livro "O pensamento selvagem" (1989), o mito e a mitologia, que estão diretamente relacionados com o mágico, são formas de conhecimento do pensamento denominado por ele como primitivo, ou melhor, pensamento dos povos sem escrita (LÉVISTRAUSS, sd.). Esse conhecimento mágico ou mítico se dá no mesmo sentido da criação do saber da sociedade ocidental moderna, ou seja, no intuito da ordenação do pensamento, ou então, numa forma de estruturação conceitual da moral social, e isto nada mais é do que o modelo fundamental clássico de pensamento da teoria estruturalista a qual o autor é filiado. Para Lévi-Strauss a ciência produzida no mundo ocidental não é nada além do que essa mesma tentativa de ordenar o modelo de pensamento da sociedade.

Portanto, em lugar de opor magia e ciência, seria melhor colocá-las em paralelo, como dois modos de conhecimento desiguais quanto aos resultados teóricos e práticos, mas não devido à espécie de operações mentais que ambas supõem e que diferem menos na natureza que na função dos tipos de fenômenos aos quais são aplicadas (LÉVI-STRAUSS, 1989, p. 28).

Pode-se concluir daí, que a magia não é o princípio da constituição da ciência, mas sim um sistema diverso, independente e bem articulado. O que 
se busca demonstrar com isso, portanto, é como o universo mágico e/ou mitológico tem uma função pedagógica na sociedade, no caso a primitiva (ou sem escrita). Da mesma forma que essa pedagogia se encontra na sociedade moderna através da crença na ciência (Santos, 2006), mas não só, como pode ser percebido na grande influência que a sociedade moderna sofre dos princípios das grandes religiões e de outros sistemas de saber.

No mesmo sentido desta percepção do mito como uma estrutura cognitiva social, outro francês, o filosofo Edgar Morin, argumenta que "as ideias, as crenças, os símbolos e os mitos são não só potências e valores cognitivos, mas também, forças de ligação/coesão social" (2001a, p. 20-21). Dessa forma, o autor crê num certo determinismo na produção social do conhecimento em que este se sobrepõe à vontade individual (aqui é possível uma aproximação das ideias do autor com a teoria de Durkheim) coordenando o que se precisa, o que se deve e o que se pode conhecer, ou seja, o conhecimento, seja advindo de crenças científicas ou mitológicas, serve socialmente como meio de controle. Em relação a isso ele argumenta que,

Ao determinismo organizador dos paradigmas e modelos explicativos associa-se o determinismo organizado dos sistemas de convicção e de crença que, quando reinam em uma sociedade, impõem a todos a força imperativa do sagrado, a força normalizadora do dogma, a força proibitiva do tabu. As doutrinas e ideologias dominantes dispõem também da força imperativa/coercitiva que leva a evidência aos convictos e temor inibitório aos outros.

O poder imperativo/proibitivo conjunto dos paradigmas, crenças oficiais, doutrinas reinantes, verdades estabelecidas, determina os estereótipos cognitivos, preconceitos, crenças estúpidas não contestadas, absurdos triunfantes, rejeições de evidência em nome da evidência, e faz reinar, sob todos os céus, os conformismos cognitivos e intelectuais (MORIN, 2001a, p. 29).

E complementa colocando que,

A normalização manifesta-se de maneira repressiva ou intimidatória; cala os que teriam a tentação de duvidar ou contes-

198 Somanlu, ano 11, n. 1, jan./jun. 2011 
tar. [...] A normalização, portanto, com os seus subaspectos de conformismo, exerce uma prevenção contra o desvio e elimina-o, se ele se manifesta (MORIN, 2001a, p. 31).

Por meio desses escritos de Morin é possível perceber exatamente o caráter coercitivo/repressivo do conhecimento mitológico socialmente construído. Não só em relação à mitologia em si, o autor argumenta sobre um todo da sociedade se referindo à cultura de uma forma geral, pois a mitologia faz parte de um complexo cultural que perpassa história, política, geografia, artes e diversos outros aspectos de uma sociedade dada. Assim, ele propõe que a sociedade é formada e formadora de indivíduos, pois ela é voltada ao interesse individual, mas fadada ao interesse coletivo (MORIN, 2001b), e é o edifício da cultura que define essa construção coletiva.

A cultura, que caracteriza as sociedades humanas, é organizada/ organizadora via o veículo cognitivo da linguagem, a partir do capital cognitivo coletivo dos conhecimentos adquiridos, das competências apreendidas, das experiências vividas, da memória histórica, das crenças míticas de uma sociedade. Assim se manifestam "representações coletivas", "consciência coletiva", "imaginário coletivo” (MORIN, 2001a, p. 19).

Dessa maneira, a cultura criada por uma sociedade, pratica ao mesmo tempo a emancipação e a subjugação dos indivíduos. Nas palavras do mesmo autor, "a cultura é coprodutora da realidade que cada um percebe e concebe. As nossas percepções estão sob controle, não apenas de constantes fisiológicas e psicológicas, mas, também, de variáveis culturais e históricas" (MORIN, 2001a, p. 25).

Toda e qualquer sociedade é, portanto, formada por uma cultura específica desenvolvida a partir dos diversos aspectos que a envolve. De maneira sucinta, Edgar Morin coloca que, "a cultura é a emergência maior da sociedade humana. [...] Trata-se de um capital de memória e organização" (2001b, p. 165). E este é um ponto de fundamental interesse aqui, pois como toda cultura se relaciona à memória e principalmente, à necessidade de organização tanto do pensamento quanto das ações sobre o espaço social, o mito ou a 
mitologia tem uma função de claro interesse de cada sociedade, agindo no sentido da produção de uma certa forma de conhecimento, como defendido por Lévi-Strauss, visando à coerção no sentido da criação de uma coesão social baseada na cultura, o que para Durkheim (1999) seria no intuito da formação de uma moral social, e que, como visto, tem um de seus pilares o mito. No entanto, a utilização dessa ferramenta cultural/coercitiva não se dá, como pode parecer, única e exclusivamente nas sociedades ditas primitivas ou sem escrita, mas também e de forma sensível nas sociedades ditas avançadas - nesse sentido, talvez não haja melhor exemplo que a já citada influência das grandes religiões monoteístas ao redor do mundo. Assim, também a utilização dos mitos enquanto um instrumento "educativo" não se dá apenas a partir do universo mágico, de um mundo fantástico, principalmente ao se pensar em sociedades de certa forma secularizadas ${ }^{4}$. E este é o ponto que será discutido no próximo tópico, a formação de mitos modernos, que podem ocorrer sem a necessidade de apelo ao fantástico, a partir da utilização de novas ferramentas, ou melhor, novas formas de conhecimento.

\section{A racionalização do mundo e a perda da mitologia mágica}

Apesar de ter havido, concentradamente nos últimos decênios ou mesmo séculos, um processo de secularização em diversas partes do mundo, em especial no ocidente, o que Max Weber chamou de "desencantamento do mundo" e Friedrich Nietzsche sentenciou como a "morte de Deus", os mitos e a mitologia continuaram e continuam a ter sua função na produção de conhecimentos, crenças e na moral social. No entanto, nesse novo contexto de um mundo onde as explicações mágicas perderam força ou mesmo foram deixadas de lado, a crença em algo que sai ao controle do indivíduo, como é o caso do mito, recai em outros aspectos que não os que vêm do céu a terra. Nesse sentido, a fé quase irrestrita do homem moderno na ciência pode ser vista como um desses aspectos.

$\mathrm{Na}$ teoria de Boaventura de Sousa Santos a construção dessa fé do homem moderno na ciência se dá de maneira a desqualificar qualquer outra

200 Somanlu, ano 11, n. 1, jan./jun. 2011 
forma de produção do conhecimento através do que ele chama de monoculturas do saber ou produção da não-existência, em que a ciência e a economia produtivista/capitalista são os cânones que devem "necessariamente" serem seguidos (Santos, 2006). Essas construções do autor nos servem aqui para compreender como elementos que diferem dessa racionalidade imposta são transformados e reconfigurados de acordo com o interesse desse "saber hegemônico". Dessa maneira, é possível, aproximar essa ideia de Boaventura com as colocações de Lévi-Strauss já vistas, uma vez que formas de conhecimento diversos não se anulam, mas tem suas funções próprias.

Retornando à hegemonia da ciência moderna, de acordo com o sociólogo inglês Anthony Giddens, é perceptível na sociedade moderna o fenômeno dos "sistemas peritos" (Giddens, 1991), que nada mais são do que uma relação de confiança dos indivíduos para com o conhecimento produzido cientificamente e que são aceitos quase universalmente na sociedade moderna. Dentre os exemplos possíveis, pode-se pensar na crença da maioria das pessoas, que em geral são leigas, de que uma construção não irá ruir sem que essas pessoas, no entanto, conheçam preceitos básicos de física e engenharia para terem fé na suposição da rigidez do edifício. Outro exemplo pode ser pensado em relação ao reconhecimento de que uma vacina será benéfica à saúde pública sem que aquelas mesmas pessoas tenham algum conhecimento sobre biotecnologia, farmácia ou medicina.

De outra maneira, porém complementar à ideia de Giddens, mas, muito mais relacionada à proposta do "desencantamento do mundo" weberiano, Jürgen Habermas argumenta em relação à colonização do que ele chama de "mundo da vida", em que o viver do dia-a-dia deixa de ser algo com pouca ou nenhuma relação com as instituições superiores ao indivíduo e passa a ser controlado por crenças externas a este, originárias dessas instituições. Dentre os exemplos possíveis, pode-se pensar no grande poder que peritos da psicologia e da pedagogia tem sobre os pais e suas atitudes para com os seus filhos, este processo pode ser visto como algo de extrema racionalização do mundo. Para Habermas, "racionalização quer dizer, antes de mais nada, ampliação dos setores sociais submentidos a padrões de decisão racional” (1980,p. 313). 
Portanto, este fenômeno se mostra como uma exacerbação daquele processo de perda das explicações mágicas, de desencantamento do mundo. Dessa forma, o interesse nesses autores, ou melhor, nessas concepções recortadas de suas teorias, se dá aqui pela necessidade de demonstrar como o desenvolvimento da sociedade levou não à perda dos mitos e da mitologia, mas apenas à transformação dessas crenças, ou dito de outra forma, apenas transferiu as referências do mundo superior (divino) para o mundo ordinário (terreno), aquelas deixaram de ser mágicas e se tornaram racionais.

Dentre as concepções propostas por Edgar Morin em seu "Método 4" (2001a), está a de que todo conhecimento é produzido segundo os contextos cultural, social e histórico que os envolve, nesse sentido ao se pensar a produção do mito na sociedade moderna racionalizada, deve-se levar em consideração esse ambiente mágico.

A partir dessa concepção de Morin e da realidade moderna colocada por Habermas, Giddens e Boaventura, se torna possível pensar a Amazônia, seus mitos e crenças nessa realidade. Este é, portanto, um trabalho de reconstrução desses aspectos culturais, sociais e históricos. A região durante muitos anos vem sendo alvo de diversos processos de colonização por parte de projetos políticos, sociais e filosóficos externos a ela, o que acabou por forçar o surgimento de novas mitologias e moldou (e vem moldando) um novo imaginário coletivo na região.

\section{Imaginário e história}

A peculiaridade do ambiente amazônico é algo que salta aos olhos a qualquer observador, a quantidade descomunal de água em seu território é algo único em regiões continentais ao redor do mundo, não à toa, a água, ou melhor, os rios são fundamentais nas relações que o homem amazônico mantém com seu meio, Leandro Tocantins foi sucinto em relação a isto ao intitular um de seus livros - "O rio comanda a vida". A ocupação do território segue, portanto, a lógica da água, por isso, como constatado por diversos estudiosos (BENCHIMOL, 2009; BATISTA, 2007.), dentre eles, por João Paes Lourei-

202 Somanlu, ano 11, n. 1, jan./jun. 2011 
ro (1995) as comunidades em geral margeiam os corpos d'água. Segundo este autor, existe dois elementos fundamentais da cultura amazônica, que seriam o isolamento e a identidade. A noção de isolamento ocorre devido às parcas relações mantidas entre esta região do Brasil com as outras áreas do território nacional, decorrente de poucas relações comerciais, pois a economia da Amazônia brasileira historicamente foi voltada para a Europa, "o fato é que a Amazônia se manteve isolada ou marginalizada em relação ao Brasil” (PAES LOUREIRO, 1995, p. 25). Mesmo hoje, a agenda econômica da região está muito mais voltada para um comércio global do que nacional, vide a produção industrial da Zona Franca de Manaus (VALLE, 2007), a soja enquanto commodities internacionais (FEARNSIDE, 2006) e a exploração mineral na Amazônia oriental (COELHO, 2006). Já em relação à identidade, nada mais natural que uma cultura seja de fato influenciada pelo seu meio e como este é único e peculiar a identidade também se torna algo bastante específica à região. Assim, nesse universo tão rico em singularidades, o homem amazônico moldou sua cultura de forma a se relacionar com o que encontrava a sua volta, dessa maneira, consequentemente, formou-se toda uma mitologia ou imaginário dessa região. Nas palavras de Paes Loureiro,

\footnotetext{
Envolvida em isolamento e mistério, a Amazônia foi construindo um sistema de vida e trabalho [...]. Uma cultura de profundas relações com a natureza, que perdurou, consolidou e fecundou, poeticamente o imaginário destes indivíduos isolados e dispersos às margens dos rios $(1995$, p. 26).
}

O imaginário existente na região é algo que difere desta forma dos de outras áreas por ter uma relação mais aprofundada com o meio natural e, dessa forma, ser mais ligado ao universo mágico, por ter sofrido menos com o processo de racionalização ocorrido em outras partes mais urbanizadas do País. De acordo com o autor, "Neste contexto, isto é, no âmbito de uma cultura dissonante em relação aos cânones urbanos, o homem amazônico, o caboclo, busca desvendar os segredos de seu mundo, recorrendo dominantemente aos mitos e à estetização" (PAES LOUREIRO, 1995, p. 26). 
No entanto, este quadro assim desenhado, tem uma maior relação com o passado das populações amazônicas do que com a realidade presente, não que aquela realidade tenha deixado de existir - mesmo porque, como dito anteriormente, o universo mágico nunca deixou de se fazer presente em toda e qualquer sociedade, não existe sociedade plenamente livre do mundo mitológico -, mas devido a diversos fatores, dentre eles pode-se pensar até mesmo o processo de desmatamento que ocorre em diversas áreas da região ou à migração do campo para a cidade, ela vem se tornando cada vez mais frágil. Nas palavras de Paes Loureiro a intenção de seu estudo era compreender a cultura amazônica,

[...] antes que ocorra uma definitiva mudança no seu ethos, em consequência das cumulativas incursões desenvolvimentistas, tantas vezes expropriatórias e desestruturadoras de sua sociedade, agravadas a partir dos anos 60 e que vêm configurando a parte triste desses trópicos (1995, p. 16).

Ou seja, também na Amazônia, mesmo com toda sua especificidade vem ocorrendo um processo de perda daquela mitologia mágica e uma, consequente, colonização ou substituição por parte de outras formas de mitos, que são impostos através da racionalidade. Apesar de, como Paes Loureiro destacou, a Amazônia ter tido um processo histórico completamente diverso e mesmo, de certa forma, à revelia do resto do território nacional, ela a partir dos anos 1960 passou a sofrer um processo de aproximação para com os preceitos nacionais, pode-se perceber isto em relação às diversas políticas públicas que passaram a serem postas em funcionamento por meio daquelas propostas desenvolvimentistas, que ainda hoje, com uma nova roupagem, regem a ação política do Estado nacional.

De fato a Amazônia passa a fazer parte de políticas de desenvolvimento nacional mais concentradamente a partir da metade do século passado, quando a política desenvolvimentista ganhou força no país, o que se deu com a chegada de Juscelino Kubitschek ao poder. No entanto, a região passou a sofrer com grandes intervenções mais concentradamente no decorrer do perí- 
odo militar, pois além da lógica desenvolvimentista já ter sua centralidade na ação política nacional, os militares somaram sua filosofia a esta prática, por isso projetos de integração nacional foram bastante perceptíveis durante seus anos no poder. "Integrar para não entregar" era o mote da ditadura no sentido de legitimar seus projetos faraônicos postos em prática na Amazônia. Mas antes de entrar na temática amazônica em si, se faz necessário compreender o desenvolvimento do sistema rodoviário nacional que devido à sua grande força deixa de ser apenas um sistema de transporte e passa a fazer parte do imaginário nacional de progresso e modernidade (COSTA et al., 2001).

Como dito acima, o modelo desenvolvimentista ganha força com JK, no entanto ele já vinha sendo aplicado há alguns anos no Brasil, desde Getúlio Vargas essa foi a forma que o Estado nacional encontrou como meio de induzir o desenvolvimento do país. A intervenção estatal se tornou, então, o meio para se chegar a este propalado fim. Devido ao contexto internacional da economia, em que a hegemonia político-econõmica inglês rui e passa às mãos dos EUA, o Brasil deixa de ser dependente do financiamento dos primeiros e passa a sofrer influência direta dos outros. Em decorrência deste fato o modelo de desenvolvimento norte-americano se tornou hegemônico no país, não à toa, opta-se pelo modelo rodoviário enquanto o principal modal do sistema de transporte nacional $1^{5}$. Nesse mesmo momento o Brasil começava a aplicar a política de substituição de importações, numa tentativa de industrialização, com este intuito e sob influência dos EUA, o país assume a indústria automobilística como prioridade número um, o que ajudou na consolidação do modelo rodoviarista nacional (BRUM, 2009).

Sob essa tutela norte-americana ocorre no Brasil um processo de aceitação do American Way of Life, ' de acordo com essa "filosofia de vida", o consumo de bens duráveis, como eletrodomésticos e carros passa a fazer parte do ideal de felicidade das pessoas. A partir dessa influência, que se deu de forma econômica, política e cultural, o país elegeu a rodovia como a principal maneira de se modernizar, ou seja, através do desenvolvimento (leia-se crescimento) econômico e da integração nacional. Essa situação fez com que surgisse uma tradição rodoviária brasileira que se tornou incontestável social- 
mente pela sua pujança perante os "adversários" - ferrovias e hidrovias -, pois a implantação de uma rodovia era a "promessa" da chegada do desenvolvimento, dessa forma as estradas se naturalizaram no imaginário nacional como o principal meio de fudar uma sociedade moderna e desenvolvida (COSTA et al., 2001). Nas palavras dos autores, "o início da era rodoviária no Brasil configurou também um ideário e um estilo de vida 'moderno' associado ao automóvel” (COSTA et al., 2001, p. 34).

Como defendido por João Paes Loureiro (1995), a Amazônia passa a se integrar de fato ao Brasil a partir dos projetos desenvolvimentistas que se tornaram hegemônicos no País dos anos de 1950 para frente. Esse processo de integração ocorreu de diversas formas, dentre elas o projeto de integração econômica com a implantação em Manaus da Zona Franca e em Belém da sede da Superintendência de Desenvolvimento da Amazônia - Sudam, e o que mais interessa aqui, a tentativa de integração geográfica (terrestre) com a implantação de inúmeras estradas. O período militar foi o momento mais pródigo desse processo de integração nacional, dentre as estradas implantadas pode-se tomar como exemplo, a Belém-Brasília, a Transamazônica e a BR319 (Manaus-Porto Velho). De acordo com Sérgio Costa e parceiros, "a última grande fase do rodoviarismo brasileiro é a exacerbação do desenvolvimentismo" (2001, p. 62) ocorrida no período militar.

Com isso é possível perceber o quanto a região amazônica sofreu com processos exógenos, políticas públicas vindas de cima para baixo, ou melhor, de Brasília para a Amazônia. O que acarretou diversas consequências socioculturais aos povos da região. Um dos fatores que contribuíram para a mudança do paradigma mitológico regional ocorreu nos governos desenvolvimentistas, em especial nos militares, através de uma de suas principais características que era o sistema de propaganda de seus feitos. No período militar isto se deu de maneira bastante forte, uma vez que a elite fardada necessitava de legitimar sua posição perante a sociedade (IANNI, 1979), vide a forma como galgaram o poder. Como colocado por Sérgio Costa e colaboradores, "as grandes obras viárias e os sonhos expansionistas da ditadura militar foram amplamente propagados por um eficiente sistema de divulgação do

206 Somanlu, ano 11, n. 1, jan./jun. 2011 
patriotismo" (2001, p. 65). Patriotismo este que se confundia com o processo de cooptação forçada da região Norte ao sistema nacional rodoviário, que reiterava a ideia-força "integrar para não entregar".

Este processo que ocorreu na Amazônia durante os anos de 1964 e 1985, se espalhou no território tendo estradas em diversas direções, se não implementadas, ao menos em projeto. $\mathrm{O}$ intuito dessa proposta era, como colocado, integrar a Amazônia ao resto do território nacional, o que de acordo com o plano inicial, acabou sendo de certa maneira bem sucedido, existem hoje, bem ou mal conservadas, estradas como a BR-163 (Cuiabá-Santarém), a Transamazônica, todas heranças do boom desenvolvimentista nacional, e outras parcialmente fora de uso como a BR-319, também herdada daquele momento. Obviamente que a estruturação dessas vias trouxe consigo uma enormidade de migrantes das regiões Sul, Sudeste e Nordeste do país, incentivadas pelo próprio governo federal (BENCHIMOL, 1981), populações que não compartilhavam da cultura e, consequentemente, da mitologia amazônica, que, além disso, estavam a mais tempo expostas ao imaginário rodoviarista como meio de indução do desenvolvimento e à própria propaganda estatal. Portanto, todos estes projetos rodoviários, especialmente pela singularidade da região amazônica, mas não só, como também pela chegada à região de pessoas com outras formações culturais, foram acompanhados de um poderoso sistema de propaganda oficial do governo militar.

Dessa forma, aqui se dá o ponto de encontro dessas grandes obras e sua influência na cultura regional. Como argumentado por Edgar Morin (2001a) a cultura é diretamente influenciada pelo meio, assim como também pela forma da construção social do conhecimento. Ao mudar radicalmente o espaço em diversas áreas da Amazônia as grandes obras ajudaram a moldar uma nova forma de pensamento por parte das populações locais, nesse sentido, pode-se mesmo pensar na maneira como essa mudança influenciou no imaginário e/ ou nos mitos regionais. A perda da preponderância do rio no dia a dia das pessoas ajuda na transformação do ethos social, pois, a estrada, se implantada, diminui a necessidade do rio como meio de locomoção, o que ajuda na deterioração do curso d'água na imaginação social. No entanto, o interesse maior, 
se dá aqui, em relação à mudança cultural através da construção do conhecimento, ou dito de outra forma, na edificação de um imaginário coletivo e como isso foi potencializado pela efetivação das estradas na região amazônica, assim como, pelo sistema de propaganda do Estado autoritário.

Além do famoso mote, já citado aqui, "integrar para não entregar" dos militares, diversas outras motivações foram utilizadas pelo sistema de propaganda oficial. Concepções de "vazio demográfico" e exotizações em geral foram utilizadas pelo regime militar como argumentos para a legitimação deste mega projeto. Sérgio Costa et al. demonstraram em seu texto como a ditadura concebia a função de suas obras, referendando em escritos de órgãos oficiais, a intenção das estradas na Amazônia era levar as velhas cidades "antes 'sitiadas pela floresta e escrava dos rios', o 'impacto do progresso', na medida em que obrigava a necessária derrubada da 'selva compacta e até então inviolada' " (2001, p. 70). Através desta sentença fica claro como a propaganda funcionava de forma a criar uma falsa expectativa nas populações de que a chegada da estrada bastaria na "transformação para melhor" das comunidades no entorno dessas vias. Argumentações em relação à chegada do progresso, do desenvolvimento, da superação do atraso, enfim, da "felicidade" (SCHOR, 2007), foram repetidamente utilizados pelos ditadores. O interessante destas concepções é que nelas podem ser percebidas de forma clara dicotomias entre dois polos de sociedades possíveis: os desenvolvidos e os não desenvolvidos.

O interesse nessa dicotomia intrínseca à propaganda oficial se dá, porque, de acordo com Edgar de Assis Carvalho (1999) a formação do imaginário social é regida por dicotomias arquetípicas, como dia/noite, céu/terra, etc., ou seja, ao utilizar de concepções bipolares em suas propagandas legitimadoras, a ditadura conscientemente ou não, colaborou na formação do mito do asfalto enquanto indutor do desenvolvimento. E, dessa maneira, ajudaram a moldar um novo imaginário social na Amazônia, no qual a imagem pré-construída de uma realidade diversa é o suficiente para a manutenção da crença de que aquilo é ou pode ser real. Nas palavras de Levi-Strauss, "esta é a originalidade do pensamento mitológico - desempenhar o papel de pensa-

208 Somanlu, ano 11, n. 1, jan./jun. 2011 
mento conceitual" (sd, p. 37). Ou seja, a criação ou indução a uma realidade construída de forma imaginária leva à formação de uma nova crença mítica popular, mesmo que essa não tenha relação com o universo fantástico.

\section{Considerações finais}

O caráter coercitivo/repressivo do conhecimento mitológico pode ser percebido na consolidação do sistema nacional de transportes, com seu rodoviarismo hegemônico, pois como se não bastasse políticas impositivas na opção pelo transporte rodoviário, foi criada uma considerável máquina de propaganda que ajudou a formar uma mitologia baseada na crença da racionalidade, pois, como visto em Morin, o conhecimento é concebido de acordo com o contexto onde é produzido e isto diz respeito à cultura, à sociedade e à história. E, como colocado, a região amazônica sofreu com uma mudança drástica em relação ao seu modus vivendi, a partir das diversas tentativas e intervenções de fato, do governo federal, de "integrá-la" ao território nacional.

Portanto, além de ter sido e continuar a ser, como em diversos casos, exemplarmente os projetos de revitalização da BR-319 e BR-163, um grande atentado à própria condição geográfica da região amazônica, isto sem dizer da questão cultural, os projetos rodoviaristas contribuem na Amazônia para a mudança do ethos e da mitologia nela presente. Pois, a coerção mitológica hoje perceptível se deu em relação à crença na estrada como meio de trazer à região o tão famigerado desenvolvimento. E através destas políticas a concepção do conhecimento mitológico na região se modifica com a própria transformação do meio, seja através da derrubada da mata ou da diminuição da necessidade dos rios como caminhos.

Ou seja, o imaginário amazônico foi neste caso colonizado e, em consequência, transportado do universo mágico para um novo mundo "desencantado", racionalizado. 


\section{Notas}

${ }^{1}$ Vide a popularidade de super-heróis como Thor ou de filmes como Tróia e de documentários sobre Vikings etc.

${ }^{2}$ Os três primeiros - Zeus, Júpter e Odin - são similares em suas mitologias, todos são os Deuses supremos e pais dos demais deuses, assim como reis das moradas divinas. Já Exu é o Orixá mensageiro entre o mundo material e espiritual numa das inúmeras mitologias africanas. Por fim, a lenda da Cobra Grande tem diversas versões em toda região amazônica.

${ }^{3}$ A relação que necessariamente deve ser entre homem e mulher por si só já é um valor da moral cristã que não admite outras formas de relação afetiva entre os sexos.

${ }^{4}$ Aqui está colocado "de certa forma" uma vez que não existe de fato nenhuma sociedade plenamente secularizada, que siga os preceitos positivistas de extrema racionalização, em que o universo mágico religioso esteja realmente excluído do contexto social.

${ }^{5}$ Como os EUA é o berço do automóvel e por ser este um ótimo produto de exportação, o Brasil sofreu pressão para assumir o modal rodoviário.

${ }^{6}$ Como o intuito deste texto não se dá em relação às motivações e/ou formas de como ocorreu esta opção, se passa por esta temática de forma superficial.

${ }^{7}$ É possível dizer que o American Way of Life faz parte do imaginário norte-americano, não à toa, ele é colocado como o sonho americano.

\section{Referências}

BATISTA, Djalma. O complexo da Amazônia: análise do processo de desenvolvimento. 2 ed. Manaus: Ed. Valer, Edua e Inpa, 2007.

BENCHIMOL, Samuel. Amazônia: formação social e cultural. 3. ed. Manaus: Ed. Valer, 2009.

- Amazônia Legal na década de 70/80: expansão e concentração demográfica. Manaus: Cedeam/UA, 1981.

BRUM, Argemiro José. O desenvolvimento Econômico Brasileiro. 26. ed. Ijuí: Ed. Unijuí, 2009.

CARVALHO, Edgar de Assis. A complexidade do imaginário. In: Leituras da Amazônia - Revista Internacional de Arte e Cultura. Ano 1. n. 1. Edua/ Stendhal, 1999. p. 119-134.

210 Somanlu, ano 11, n. 1, jan./jun. 2011 
COELHO, Maria Célia Nunes. Região de Carajás: Passado, presente e futuro da região e dos movimentos sociais. In: FORLINE, Louis. MURRIETA, Rui. \& VIEIRA, Ima. (Orgs.). Amarônia além dos 500 anos. Belém: Museu Paraense Emílio Goeldi, 2005.

COSTA, Sérgio et al. Modernização negociada: expansão viária e riscos ambientais no Brasil. Brasília: Ed. Ibama, 2001.

DURKHEIM, Émile. As regras do método sociológico. São Paulo: Martins Fontes, 1999.

FEARNSIDE, Philip Martin. O cultivo da soja: como ameaça para o meio ambiente na Amazônia Brasileira. In: FORLINE, Louis. MURRIETA, Rui. \& VIEIRA, Ima. (Orgs.). Amazônia além dos 500 anos. Belém: Museu Paraense Emílio Goeldi, 2005.

GIDDENS, Anthony. As consequências da modernidade. São Paulo: Ed. UNESP, 1991.

HABERMAS, Jurgen. Técnica e ciência enquanto "ideologia". In: Coleção Os pensadores. São Paulo: Abril Cultural, 1980. p. 313-337.

IANNI, Octávio. Ditadura e agricultura - O desenvolvimento do capitalismo na Amazônia 1964/1978. Rio de Janeiro: Civilização Brasileira, 1979.

MORIN, Edgar. O método 4: as ideias - habitat, vidas, costumes, organização. Porto Alegre: Ed. Sulina, 2001a.

- O método 5: a humanidade da humanidade. 2. ed. Porto Alegre: Ed. Sulina, 2001b.

LÉVI-STRAUSS, Claude. Mitos e significados. Lisboa: Edições 70, sd. O pensamento selvagem. São Paulo: Papirus, 1989.

PAES LOUREIRO, João. Cultura Amazônica: uma poética do imaginário. Belém: CEJUP, 1995. 
SANTOS, Boaventura de Sousa. A gramática do tempo: para uma nova cultura política. São Paulo: Cortez, 2006 (Coleção para um novo senso comum, vol. 4). SCHOR, Tatiana. Abram alas que eu quero passar: o desfile do automóvel na cidade de Manaus. In: Somanlu. Ano 7. n. 1. Jan./Jun., 2007. p. 55-69.

VALLE, Izabel. Globalização e reestruturação produtiva: um estudo sobre a produção offshore em Manaus. Manaus: Edua, 2007.

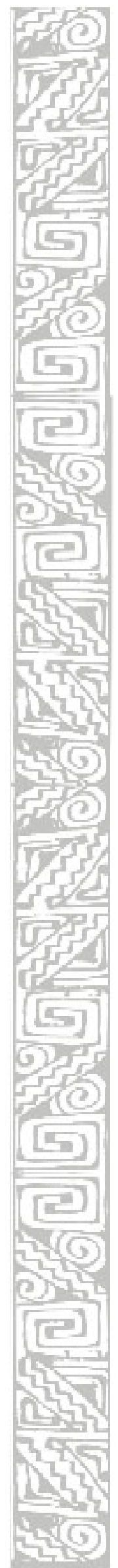

212 Somanlu, ano 11, n. 1, jan./jun. 2011 